\title{
SISTEM PAKAR UNTUK MENDIAGNOSA PENYAKIT PADA TANAMAN JAGUNG DENGAN METODE BAYES
}

\author{
Hengki Tamando Sihotang \\ Teknik Informatika \\ STMIK Pelita Nusantara,JL.Iskandar Muda No.1. Medan, Sumatera Utara, Indonesia 20154 \\ hengki_tamando@yahoo.com
}

\begin{abstract}
Abstark
Banyak nya penyakit pada jagung saat ini dapat membuat petani bingung dalam menentukan ataupun memilih jenis pengobatan yang sesuai dengan penyakit jagung tersebut. Ini yang membuat petani susah mendapatkan hasil karena mereka tidak bisa melakukan pendiagnosaan yang tepat, sehingga tingkat produktifitas menurun. Sistem pakar berbasis komputer dapat digunakan dalam membantu memecahkan masalah dalam hal membantu setiap petani dalam menentukan pilihan pengobatan. Adapun metode yang digunakan dalam mendiagnosa penyakit pada tanaman jagung adalah Metode Bayes, dimana setiap alternatif yang disediakan akan dilakukan perangkingan untuk memperoleh hasil terbaik. Hasil yang dihasilkan berupa pengurutan data penyakit pada tanaman jagung yang dijadikan sebagai alat bantu dalam pengambilan keputusan bagi petani. Sistem yang dibangun diharapkan mampu membantu petani dalam memilih pengobatan yang tepat dan sesuai penyakit pada jagung.
\end{abstract}

Kata Kunci : Sistem Pakar, Metode Bayes, jagung.

\begin{abstract}
Abstrak
Many of the diseases in corn today can make farmers confused in determining or choosing the type of treatment in accordance with the disease of corn. This is what makes farmers hard to get results because they can not perform proper diagnosis, so that the level of productivity decreases. Computer-based expert systems can be used to help solve problems in terms of assisting each farmer in determining treatment options. The method used in diagnosing the disease in corn plants is Bayes Method, where each alternative provided will be done ranking to obtain the best results. The resulting results are sorting of disease data on corn plants that serve as a tool in decision-making for farmers. The built system is expected to help farmers in choosing appropriate treatment and appropriate diseases in corn.
\end{abstract}

Kata Kunci : Expert System, Bayes Method, corn.

\section{PENDAHULUAN}

Di Indonesia, tenaga tani yang ahli pada bidang penyakit tanaman Jagung masih terbatas, baik dari segi jumlah dan waktu kerja. Dalam menyelesaikan serangan hama dan penyakit yang menyerang tidak sedikit dari petani melakukan kesalahan dalam mengatasi permasalahan yang dihadapi. Sehingga dengan pembuatan sistem pakar untuk mendiagnosa penyakit tanaman jagung ini diharapkan bisa membantu petani untuk mengatasi permasalahan dengan memberikan solusi yang baik. Proses pembuatan sistem pakar ini metode kepastiannya teorema bayes dimana metode ini didasarkan dari kondisi awal dimana kondisi awal merupakan kondisi gejala-gejala yang ada kemudian dikenakan aturan yang sudah ditentukan lalu diambil nilai kebenaran yang paling besar untuk menentukan kesimpulan dan solusi dari gejala yang disebutkan sebelumnya.
Namun penelitian sistem pakar tersebut adalah tentang mendeteksi hama pada tanaman jahe tanpa pembuatan jenis penyakit yang terdeteksi, berbeda dengan sistem pakar menggunakan teorema bayes ini adalah untuk mendiagnosa penyakit pada tanaman jagung dan gejala-gejala yang menyebabkan penyakit tersebut. Berdasarkan uraian diatas, penulis tertarik membuat sistem pakar dengan harapan pembuatan sistem pakar ini bisa berjalan dengan lancar serta bermanfaat bagi masyarakat petani tanaman Jagung dalam melestarikan Jagung serta meningkatkan hasil panen masyarakat.

\section{METODE}

Teorema Bayes Penelitian yang dilakukan menyebutkan bahwa metode Bayes dapat digunakan untuk mengembangkan Sistem Cerdas untuk diagnosa penyakit. Pada penelitian ini metode Bayes diimplementasikan untuk mendiagnosis penyakit jantung dan membantu praktisi kesehatan untuk membuat keputusan 
klinis yang cerdas. Hasil penelitian dapat memberikan pengobatan yang efektif, dan juga membantu untuk mengurangi biaya pengobatan [1].

Pembangunan Aplikasi Sistem Pakar untuk Diagnosis Penyakit Tanaman Padi. Pada penelitian ini, metode forward chaining digunakan untuk melakukan diagnosa hama yang menyerang tanaman padi dengan melihat ciri-ciri yang muncul di tanaman tersebut. Pada beberapa kasus yang cirinya tidak ada pada aturan yang dibuat, maka dimungkinkan akan muncul hasil dimana hama yang menyerang tidak diketahui [2].

Sistem pakar untuk mendiagnosa hama dan penyakit tanaman bawang merah menggunakan certainty factor. Penelusuran faktanya menggunakan forward chaining yaitu penelusuran yang dimulai dari fakta fakta untuk menguji kebenaran hipotesis [3]

Dalam keseharian banyak masalah yang tidak dapat dimodelkan secara lengkap dan konsisten. Suatu penalaran dimana adanya penambahan fakta baru mengakibatkan adanya ketidak konsistenan, dengan ciri ciri sebagai berikut

1. Adanya ketidakpastian

2 Adanya perubahan pada pengetahuan

3. Adanya penambahan fakta baru dapat mengubah konklusi yang sudah terbentuk.

Untuk mengatasi masalah ketidakpastian maka dapat digunakan penalaran statistik. Teori Bayes digunakan sebagai alat pengambil keputusan untuk memperbaharui tingkat kepercayaan diri dari suatu informasi. Metode ini banyak diterapkan pada hal-hal yang berkenaan dengan diasgnosa secara statistik yang berhubungan dengan probabilistik serta kemungkinan dari penyakit dan gejala gejala yang berkaitan. Contoh Kasus Penyakit Busuk Tongkol.

$$
\begin{aligned}
& \boldsymbol{P}(\boldsymbol{H} \backslash \boldsymbol{E})=\frac{\boldsymbol{P}(\boldsymbol{E} \backslash \boldsymbol{H}) * \boldsymbol{P}(\boldsymbol{H})}{\boldsymbol{P}(\boldsymbol{E})} \\
& \mathrm{P}(\mathrm{H} \mid \mathrm{E})=\begin{array}{c}
\text { Probabilitas hipotesis H } \\
\text { jika diberikan evidence E. }
\end{array} \\
& \mathrm{P}(\mathrm{E} \mid \mathrm{H})=\begin{array}{l}
\text { Probabilitas munculnya } \\
\text { evidence E, jikadiketahui } \\
\text { hipotesis H benar. }
\end{array} \\
& \mathrm{P}(\mathrm{H}) \quad \begin{array}{l}
\text { Probabilitas hipotesis H (menurut } \\
\text { hasil sebelumnya) tanpa } \\
\text { memandang evidence apapun. }
\end{array}
\end{aligned}
$$

$\mathrm{P}(\mathrm{E}) \quad=$ Probabilitas evidence $\mathrm{E}$.

Penyakit Jagung memiliki tingkatan penyakit antara lain :
TABEL I

TABEL PENYAKIT

\begin{tabular}{lll}
\hline A & BULAI & 0,5 \\
\hline B & KARAT & 0,6 \\
D & GOSONG & 0,6 \\
F & BUSUKTONGKOL & 0.7 \\
\hline
\end{tabular}

Adapun gejala-gejala dari penyakit Jagung dapat dilihat pada tabel seperti dibawah ini:

TABEL II

TABEL GEJALA

\begin{tabular}{|c|l|}
\hline Node. & \multicolumn{1}{|c|}{ Gelala } \\
\hline G1 & $\begin{array}{l}\text { Tanamanjagung yang berumur 2-3 } \\
\text { minggu mempunyai daun menguning kaku } \\
\text { dan meruncing }\end{array}$ \\
\hline G2 & $\begin{array}{l}\text { Tanamanjagung yang berumur 3-5 minggu } \\
\text { menunjukkan tanda-tanda daun yang baru } \\
\text { muncul menguning, pertumbuhan lambat, }\end{array}$ \\
& $\begin{array}{l}\text { tongkol hanya berbiji sedikit, produksi } \\
\text { turun hingga 50\% }\end{array}$ \\
\hline G3 & $\begin{array}{l}\text { Tanamanjagung berumur 5 minggu, } \\
\text { daunnya terdapat garis-garis kuning. }\end{array}$ \\
\hline G4 & $\begin{array}{l}\text { Penyakit karat daun muncul ketika } \\
\text { tanaman akan berbunga }\end{array}$ \\
\hline G5 & $\begin{array}{l}\text { Bercak-bercak kuning kemerahan pada } \\
\text { daun, dan kelobot jagung- }\end{array}$ \\
\hline G6 & $\begin{array}{l}\text { Curah hujan tinggi dan angin yang } \\
\text { kencang }\end{array}$ \\
\hline G7 & $\begin{array}{l}\text { tongkol jagung berwama merah atau } \\
\text { merah kecoklatan dan busuk } \\
\text { man }\end{array}$ \\
\hline
\end{tabular}

Contoh Kasus Penyakit Busuk Tongkol Ani melakukan diagnosa dengan menjawab pertanyaan sesuai dengan gejala berikut :

$$
\begin{aligned}
\mathrm{G} 2 & =0.5=\mathrm{P}\left(\mathrm{E} \mid \mathrm{H}_{1}\right) \\
\mathrm{G} 3 & =0.75=\mathrm{P}\left(\mathrm{E} \mid \mathrm{H}_{2}\right) \\
\mathrm{G} 5 & =0.9=\mathrm{P}\left(\mathrm{E} \mid \mathrm{H}_{3}\right)
\end{aligned}
$$

Untuk mancari semesta dapat dijumlahkan dari Hipotesa yang di atas :

$$
\begin{aligned}
& \sum_{\mathrm{k}=1}^{5}=\mathrm{G} 2+\mathrm{G} 3+\mathrm{G} 5 \\
& =0.5+0.75+0.9 \\
& =2.15
\end{aligned}
$$

Setelah didapat penjumlahan di atas, maka didapatlah rumus untuk menghitung semesta adalah sebagai berikut :

$$
\begin{aligned}
& \mathrm{P}(\mathrm{H} 2)=\frac{H 2}{\sum_{\mathrm{k}=1}^{5}}=\frac{0.5}{2.15}=0.23255 \\
& \mathrm{P}(\mathrm{H} 3)=\frac{H 3}{\sum_{\mathrm{k}=1}^{5}}=\frac{0.75}{2.15}=0.34883 \\
& \mathrm{P}(\mathrm{H} 5) \quad \frac{H 5}{\sum_{\mathrm{k}=1}^{5}}=\frac{0.9}{2.15}=0.41860
\end{aligned}
$$

Setelah mendapatkan nilai $\mathrm{P}\left(\mathrm{H}_{\mathrm{i}}\right)$ probabilitas hipotesis $\mathrm{H}$ tanpa memandang evidence apa pun, maka langkah selanjutnya adalah sebagai berikut : 


$$
\begin{aligned}
\sum_{\mathrm{k}=1}^{5}= & P(H i) * P(E \mid H i-n) \\
= & \mathrm{P}\left(\mathrm{H}_{2}\right) * \mathrm{P}\left(\mathrm{E} \mid \mathrm{H}_{2}\right)+\mathrm{P}\left(\mathrm{H}_{3}\right) * \mathrm{P}\left(\mathrm{E} \mid \mathrm{H}_{3}\right)+ \\
& \mathrm{P}\left(\mathrm{H}_{5}\right) * \mathrm{P}\left(\mathrm{E} \mid \mathrm{H}_{5}\right) \\
= & (0,23255 * 0.5)+(0.34883 * 0.75)+ \\
& (0.41860 * 0.9) \\
= & 0.116279+0.261628+0.376744 \\
= & 0.754651
\end{aligned}
$$

Setelah mendapatkan nilainya, maka langkah selanjutnya mencari nilai $\mathrm{P}(\mathrm{Hi} \mid \mathrm{E})$ atau probabilitas hipotesis Hi benar jika diberikan nilai evidence E.

$$
\begin{aligned}
& \mathrm{P}(\mathrm{Hi} \mid \mathrm{E})=e^{x}=\frac{P(E \mid H i) * P(H i)}{\sum_{k=1}^{5} P(E \mid H k) * P(H k)} \\
& \mathrm{P}(\mathrm{H} 1 \mid \mathrm{E})=\frac{0.5 * 0.23255}{0.754651}=0.154083 \\
& \mathrm{P}(\mathrm{H} 2 \mid \mathrm{E})=\frac{0.75 * 0.3488}{0.754651}=0.346687 \\
& \mathrm{P}(\mathrm{H} 3 \mid \mathrm{E})=\frac{0.9 * 0.41860}{0.754651}=0.49923
\end{aligned}
$$

Setelah mendapatkan seluruh nilai $\mathrm{P}(\mathrm{Hi} \mid \mathrm{E})$, maka jumlahkan seluruh nilai bayesnya dengan rumus sebagai berikut:

$$
\begin{aligned}
\sum_{\mathrm{k}=1}^{\mathrm{n}} \text { Bayes }= & \text { Bayes } 1+\text { Bayes } 2+\text { Bayes } 3 \\
& + \text { Bayes5 }+ \text { Bayes } 7 \\
= & (0.5 * 0.154083)+\left(0.75^{*}\right. \\
& 0.346687)+(0.9 * 0.49923) \\
= & 0.077042+0.260015+0.449307 \\
= & 0.786364 * 100 \% \\
= & 78.636 \%
\end{aligned}
$$

\section{HASIL DAN PEMBAHASAN}

\section{A. Perancangan Sistem}

UML (Unified Modelling Language) adalah bahasa pemodelan untuk sistem atau perangkat lunak yang berparadigma berorientasi objek. Pemodelan (modelling) sesungguhnya digunakan penyederhanaan permasalahan permasalahan yang kompleks sedemikian rupa sehingga lebih mudah dipelajari dan dipahami. Dalam menganalisa dan merancang suatu basis data dapat digunakan diagram UML (Unified Modelling Language). UML merupakan salah satu tool model untuk merancang pemodelan software yang berbasis object oriented. Perancangan antarmuka yang dibuat dapat dilihat pada UML diagram sebagai berikut:

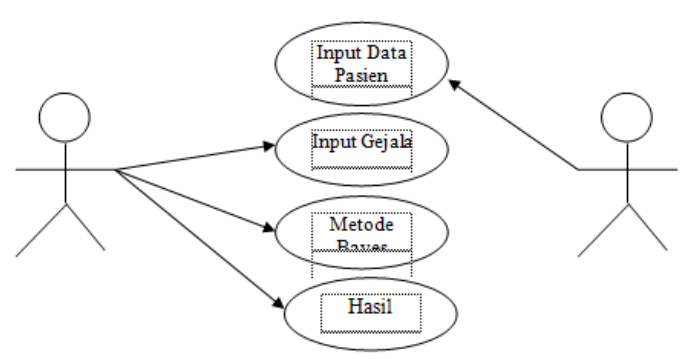

Gambar 1. Perancangan Antarmuka.

\section{B. Implementasi Sistem}

Pada tahap implementasi sistem peneliti menggunakan spesifikasi perangkat keras dan lunak untuk implementasi sistem, karena aplikasi ini masih diujicobakan didalam momputer penulis.

1. Kebutuhan Perangkat Lunak.

Adapun prangkat lunak yang diperlukan dalam pembuatan aplikasi yaitu sebagai berikut :

1. Operating system Windows 7

2. Microsoft Visual Studio 2010

3. Crystal Reports

2. Kebutuhan Perangkat Keras.

Adapun prangkat keras yang diperlukan dalam pembuatan aplikasi yaitu sebagai berikut

1. Motherboard Intel

2. Processor Core i3

3. Harddisk $300 \mathrm{~GB}$

4. RAM 4GB

5. Keyboard Standard

6. Mouse

2. Tahapan Implementasi Sistem.

1. Halaman Login.

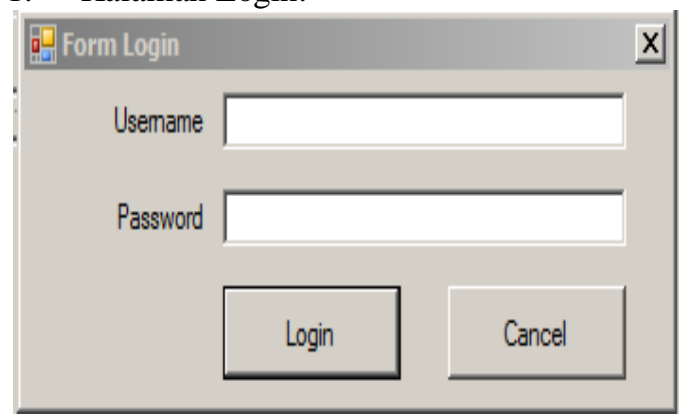

Gambar 2. Halaman Login.

Halaman login merupakan halaman pertama muncul ketika menjalankan aplikasi. Halaman ini sebagai keamanan agar tidak sembarangan orang dapat menggunakan aplikasi ini. 


\section{Halaman Utama.}

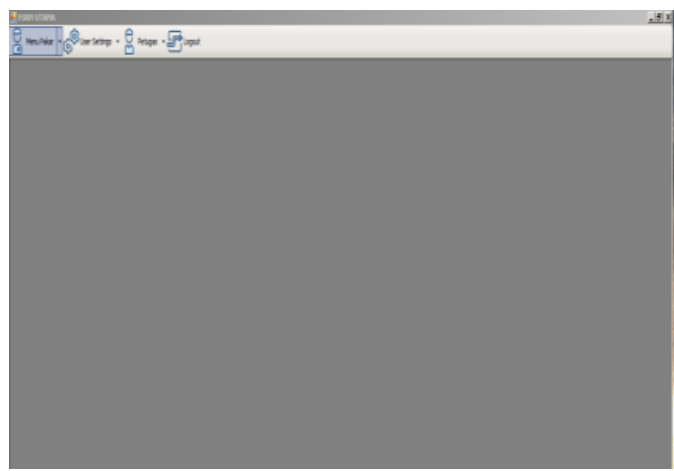

Gambar 3. Halaman Utama

Halaman utama ini merupakan halam dimana semuan fitur untuk menjalankan program disediakan.

\section{HalamanTambah Data Penyakit.}

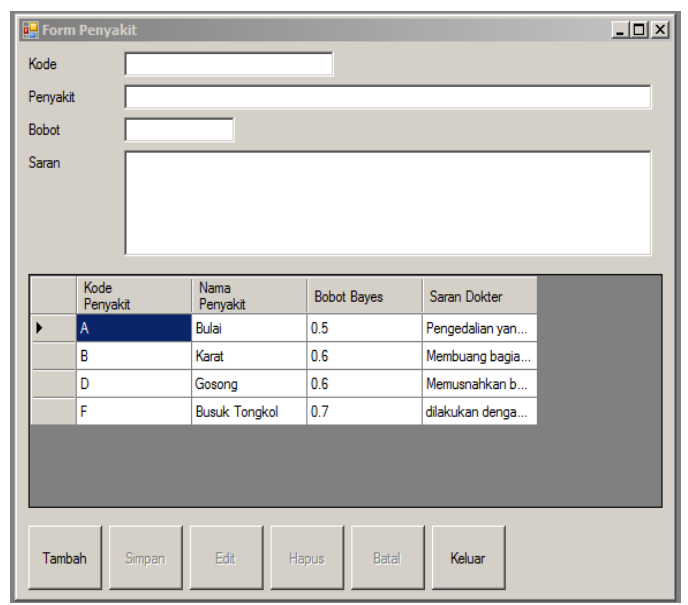

Gambar 4. Halaman Input Data Penyakit.

Halaman input data kriteria merupakan halaman untuk menginput data-data penyakit pada jagung.

\section{Halaman Input Data Gejala.}

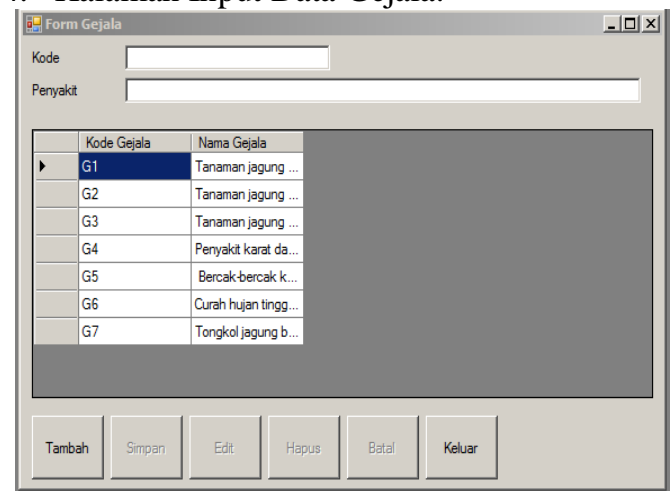

Gambar 5. Halaman Input Data Gejala.
Halaman input data gejala merupakan halaman untuk menginput data gejala - gejala yang ada pada penyakit jagung.

\section{Halaman Input Data Rule.}

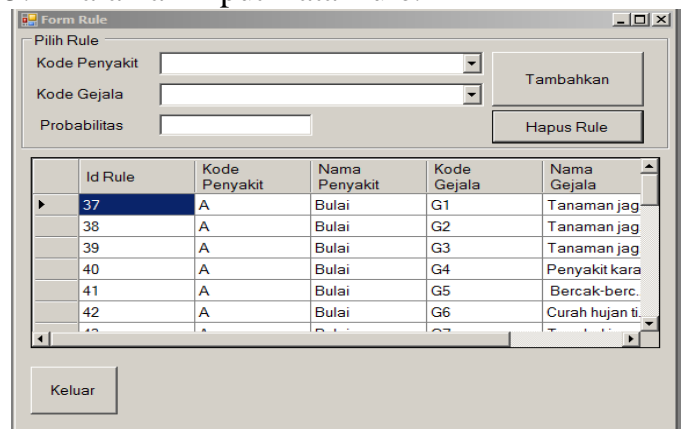

Gambar 6.Halaman Input Data Rule Pada Setiap Penyakit.

Halaman input data alternatif merupakan halaman untuk menginput data rule yang ada pada setiap penyakit dan gejala.

\section{Halaman Input User.}

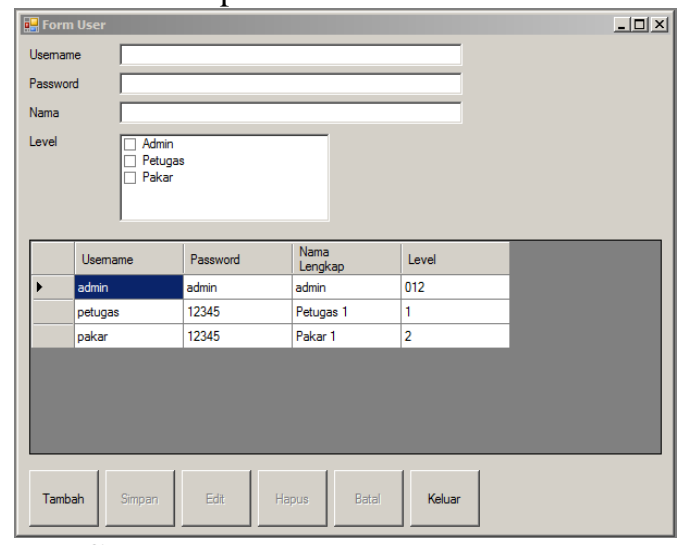

Gambar 7.Halaman Input Data User.

Halaman input data User ini merupakan tampilan untuk setiap pengguna aplikasi bagi itu admin dan petugas dan pakar.

\section{Halaman Data Petugas .}

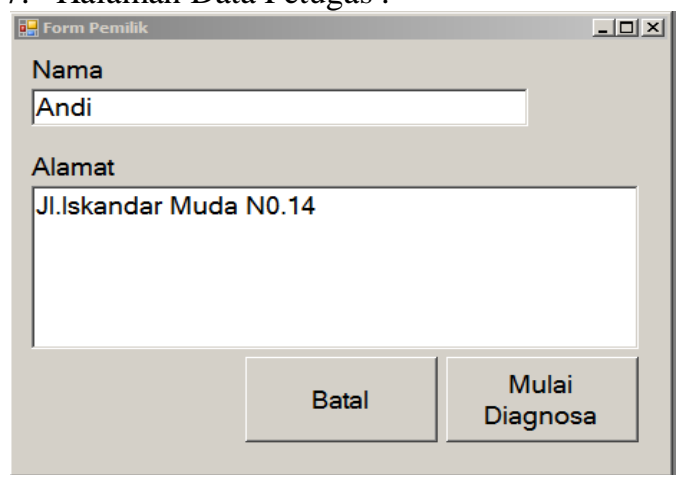

Gambar 8. Halaman Data Petugas. 
Halaman Data petugas ini merupakan tampilan untuk memasukkan data pada saat ingin melakukan konsultasi.

\section{Halaman Data Diagnosa}

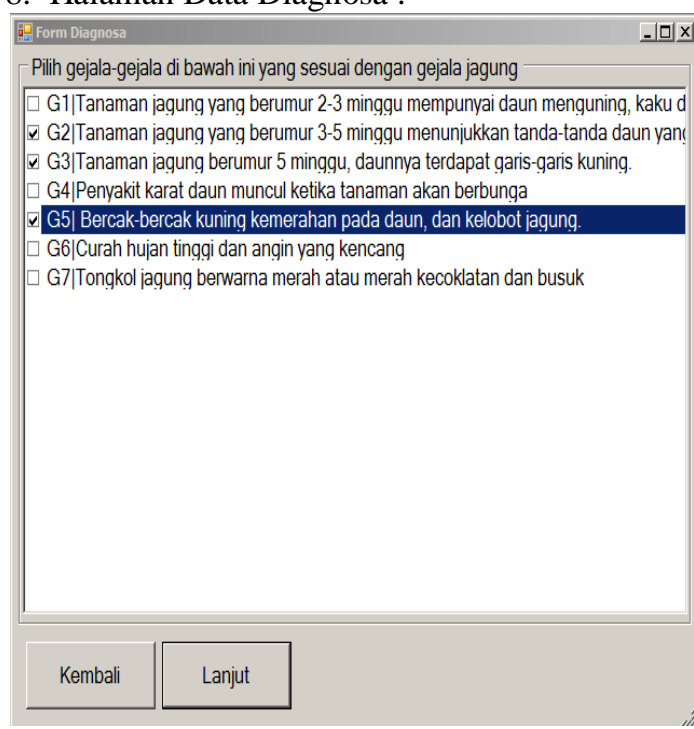

Gambar 9. Halaman Pertanyaan Pada Diagnosa.

Halaman pertanyaaan diagnosa ini merupakan tampilan untuk menjawab setiap pertanyaan dari pakar pada setiap gejala-gejala yang terjadi pada penyakit jagung yang dilihat.

\section{Halaman Hasil Diagnosa.}

\begin{tabular}{|c|c|c|}
\hline \multicolumn{2}{|l|}{ 國Form Hasil } & $-(\square) \underline{x}$ \\
\hline \multicolumn{3}{|c|}{ Nomor Diagnosa $\longdiv { 2 9 }$} \\
\hline \multicolumn{3}{|c|}{ Nama Pemilik $\quad$ Andi } \\
\hline \multicolumn{3}{|c|}{$\begin{array}{ll}\text { Alamat } & \text { Jl.Iskandar Muda N0.14 }\end{array}$} \\
\hline \multicolumn{3}{|c|}{ Tanggal Diagnosa $\quad$ Tanggal 01-11-2017 Jam 06:24 } \\
\hline \multicolumn{3}{|c|}{-Hasil Diagnosa dan Hasil - } \\
\hline \multicolumn{2}{|c|}{ Diagnosa Penyakit Busuk Tongkol } & $\begin{array}{l}\text { Nilai : } \\
0.86968525676\end{array}$ \\
\hline \multicolumn{3}{|l|}{ Saran - } \\
\hline \multicolumn{3}{|c|}{$\begin{array}{l}\text { Saran dari sistem pakardilakukan dengan pergiliran tanaman, membakar bagian } \\
\text { tanaman yang terserang dan menanam varietas yang tahan. }\end{array}$} \\
\hline Keluar & & \\
\hline
\end{tabular}

Gambar 10. Halaman Hasil Diagnosa.

Halaman hasil diagnose ini merupakan tampilan yang berisikan hasil akhir dari konsultasi dan menampilkan jenis penyakit dan saran yang diberikan oleh pakar pada penyakit jagung yang ditentukan.
10 Halaman Laporan .

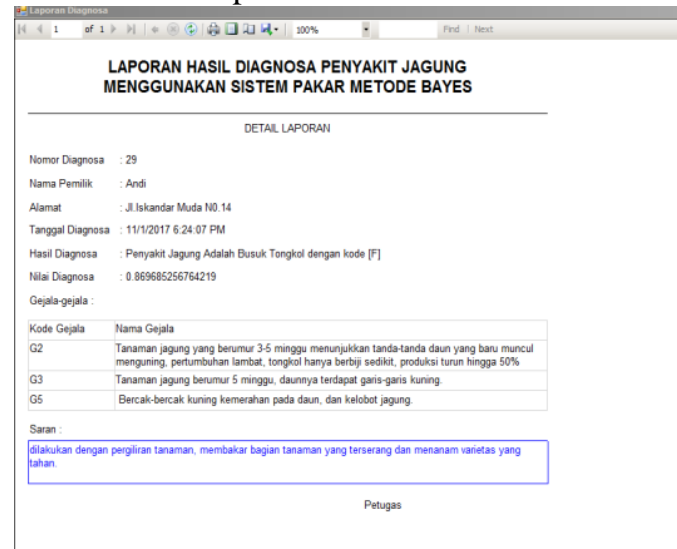

Gambar 11. Halaman Laporan Akhir.

Halaman laporan merupakan hasil dari konsultasi yang dilakukan dan nantinya bias dicetak untuk dibawa oleh konsumen yang konsultasi. .

\section{IV.KESIMPULAN}

Dari hasil pengujian terhadap Aplikasi Sistem Pakar yang di bangun, kesimpulannya adalah program aplikasi sistem pakar dapat menyelesaikan masalah yaitu bisa menampilkan hasil diagnosa dengan cepat dan tepat berdasarkan gejala-gejala yang di masukkan oleh user.

Untuk membuat hasil diagnosa menjadi sangat valid, maka data gejala yang di masukkan oleh seorang administrator / pakar kedalam suatu data penyakit, harus lengkap artinya gejala-gejala yang bisa mengarah ke suatu penyakit tersebut harus di masukkan secara lengkap karena kesimpulan hasil diagnosa yang di tampilkan di hitung secara otomatis oleh sistem aplikasi yaitu banyaknya gejala yang dipilih oleh user di bagi dengan banyaknya gejala yang di miliki suatu penyakit.

\section{REFERENSI}

[1] Tuswanto., Fadlil, Abdul., 2013, "Sistem Pakar Untuk Mendiagnosa Hama dan Penyakit Tanaman Bawang Merah Menggunakan Certainty Factor", Jurnal Sarjana Teknik Informatika, Vol. 1, No. 1.

[2] S.P. Adam, A. Parveen, "Prediction System For Heart Disease Using Naive Bayes", International Journal of Advanced Computer and Mathematical Sciences, vol 3, no. 3, pp 290-294, 2012.

[3] Sofa, R., dkk., 2009, "Pembangunan Aplikasi Sistem Pakar untuk Diagnosis Penyakit Tanaman Padi”, Jurnal Algoritma 
Sekolah Tinggi Teknologi Garut, Vol. 09, No. 03, pp. 1- 8 .

[4] Sihotang, Hengki Tamando. "Sistem Pakar Mendiagnosa Penyakit Kolesterol Pada Remaja Dengan Metode Certainty Factor (Cf) Berbasis Web." Jurnal Mantik Penusa, vol. 15, no. 1, 2014, pp. 16-23.

[5] Janer Irma Sari, Sulindawaty, Hengki Tamando Sihotang. "Implementasi Penyembunyian Pesan Pada Citra Digital Dengan Menggabungkan Algoritma HILL Cipher Dan Metode Least Significant BIT (LSB)." Jurnal Mantik Penusa, vol. 1, no. 2, 2017, pp. 1-8.

[6] Marbun, Murni, et al. "Perancangan Sistem Perencanaan Jumlah Produksi Roti Menggunakan Metode Fuzzy Mamdani." Jurnal Mantik Penusa, vol. 20, no. 1, 2016, pp. 48-54.

[7] Riandari, Fristi, et al. "Sistem Pendukung Keputusan Menggunakan Metode Topsis Dalam Memilih Kepala Departemen Pada Kantor Balai Wilayah Sungai Sumatera II Medan." Journal Of Informatic Pelita Nusantara, vol. 2, no. 1, 2017, pp. 6-13, http://e-

jurnal.pelitanusantara.ac.id/index.php/JIPN /article/view/272/170.

[8] Sihotang, Hengki Tamando. "Perancangan Aplikasi Sistem Pakar Diagnosa Diabetes Dengan Metode Bayes." Jurnal Mantik Penusa, vol. 1, no. 1, 2017, pp. 36-41, http://e-

jurnal.pelitanusantara.ac.id/index.php/mant $\mathrm{ik} /$ article/view/280.
[9] Sihotang, Hengki Tamando, and Maria Siboro. "Aplikasi Sistem Pendukung Keputusan Penentuan Siswa Bermasalah Menggunakan Metode Saw Pada Sekolah Smp Swasta Mulia Pratama Medan.” Journal of Informatics Pelita Nusantara, vol. 1, no. 1, 2016, pp. 1-6.

[10] Simangunsong, Agustina, et al. "Perancangan Aplikasi Sistempakar Menggunakan Metode Bayes Untuk Diagnosa Gejala Asma Pada Puskesmas Deli Tua." Journal of Informatics Pelita Nusantara, vol. 2, no. 1, 2017, pp. 14-21, http://e-

jurnal.pelitanusantara.ac.id/index.php/JIPN /article/view/273/171.

[11] Simanjorang, R.Mahdalena, et al. "Sistem Pendukung Keputusan Penentuan Penerima Bahan Pangan Bersubsidi Untuk Keluarga Miskin Dengan Metode AHP Pada Kantor Kelurahan Mangga.” Journal Of Informatic Pelita Nusantara, vol. 2, no. $1, \quad 2017, \quad$ pp. 22-31, http://ejurnal.pelitanusantara.ac.id/index.php/JIPN /article/view/274/172. 